\title{
DE VERBREIDING VAN HET MATRIARCHAAT IN HET LANDSCHAP INDRAGIRI.
}

\author{
DOOR
}

\author{
A. F. P. GRAAFLAND 1 .
}

Stroomafwaarts van Tjerenti vormt het plaatsje Tambangan de grens tusschen Kwantan en het landschap Indragiri, dat voornamelijk bestaat uit het stroomgebied van den benedenloop der Batang Kwantan 2.

Om tot een duidelijk overzicht te geraken omtrent de verbreiding van het natriarchaat in dit gedeelte van Sumatra, kan eene korte schets der vroegste geschiedenis van Indragiri het hare bijdragen.

Ongeveer in het begin der 14e eeuw werd dit landschap door koloniseerende Menangkabauers bevolkt, die volgens de legende, onder hunne hoofden $\mathrm{To}^{\varsigma}$ Patih en $\mathrm{To}^{s}$ Gagah Katoemenggoengan, alsmede diens hoeloebalang Sri Nata Tjerkau Tjoendiq, zich hoofdzakelijk vestigden aan de monding van het riviertje Indragiri, waar dit zich bij het tegenwoordige Pěkan Toewa in de Batang Kwantan stort.

Onder deze kolonisten moet het matriarchaat algemeen hebben bestaan. In het oog houdende hetgeen door Dr. Van der Tuuk en Dr. Wilken omtrent de bovengenoemde in de legende ook hier voor-

${ }^{1}$ Naar aanleiding van een door het Bestuur van het Koninklijk Instituut gedaan verzoek, werd door Z. E. den Minister van Koloniën van de verhandeling van den Heer G. A. Wilken "De verbreiding van het matriarchaat op Sumatra", voorkomende in deel III van dit tijdschrift, blz. $163 \mathrm{vv}$., ten vorigen jare, een aantal exemplaren naar Indië gezonden, ter uitreiking aan de ambtenaren op Sumatra, met uitnoodiging, onderzoekingen in te stellen, ten einde de bestaande leemten aan te vullen. De volgende nota is de eerste, die het Instituut mocht ontvangen. Moge die spoedig door meerdere, even volledige, bijdragen worden gevolgd. Behoudens enkele wijzigingen in taal en stijl, is het stuk onveranderd afgedrukt. (Redactie).

${ }^{2}$ Bij de lezing van dit opstel kan met vrucht worden geraadpleegd de schetskaart, voorkomende in het werkje: Graafland, Schetsen uit Indragiri. Batavia, G. Kolff \& Co., 1889. (Redactie). 
komende ambtstitels is opgemerkt ${ }^{3}$, mag het waarschijnlijk genoemd worden, dat zich twee soekoe's uit Menangkabau hier hebben neergezet, waartusschen het jus connubii bestond. Wanneer toch hier sprake was van twee staatkundige partijen, die min of meer tegenover elkaar stonden, moet het verwondering wekken, dat zij zich gezamenlijk hierheen begaven en in alles zoo eensgexind optraden.

Iangzamerhanıl schijnt, om welke reden ook, onder de kolonisten de wensch ontstaan te zijn, om een vorst aan hun hoofd te zien. De $\mathrm{To}^{\varepsilon}$ Patih en $\mathrm{To}^{\varepsilon}$ Toemenggoeng, die niet voor deze waardigheid wenschten in aanmerking te komen, besloten aldus eenen vorst te zoeken. Zij maakten een vlot, waarbij echter het merkwaardige geval zich voordeed, dat houtsoorten, die gewoonlijk op het water dreven, toen deze voor dit doel zouden gebruikt worden, zonken, zoodat de $\mathrm{To}^{5}$ Patih ten einde raad een koelim-stam omhakte: het zware stuk hout dreef en toonde zich een uitstekend materiaal voor het benoodigde vlot. Toen het te water moest gelaten worden, riepen $\mathrm{de}^{\mathrm{T}} \mathrm{To}^{5}$ Toemenggoeng en $\mathrm{To}^{\varsigma}$ Patih hunne kinderen om hen hierbij te helpen, doch deze weigerden; hierop richtten zij het verzoek tot hunne zusterskinderen, die dadelijk hieraan voldeden, waarop door hen bepaald werd, dat de nalatenschap voortaan op de zusterskinderen zou moeten overgaan.

Omtrent deze voorstelling van den oorsprong der zoogenaamde adat-kamanakan moge eene verwijzing naar het hierover voorkomende bij Dr. Wilken "De verbreiding van het matriarchaat op Sumatra", blz. 25, volstaan. Niet toch op Indragirischen bodem ontstond deze instelling; zij werd hier aangebracht uit Menangkabau.

De $\mathrm{To}^{\leq}$Patih en $\mathrm{To}^{\leq}$Toemenggoeng vonden een prins, een zoon van Sultan Mohammad Sjah, de laatste vorst, die vóór de Portugeesche invasie, op het einde der $15^{\mathrm{e}}$ en in het begin der $16^{\mathrm{e}}$ eeuw, te Malakka regeerde, dien zij tot Soetan verhieven. Langzamerhand breidde zich hierdoor de Djohorsche invloed uit en kwamen ook Djohorsche kolonisten zich in dit landschap vestigen.

De invloed hiervan op de inrichting van het bestuur en op de taal, maar bovenal op de aloude landsinstellingen, de adat-poesaka, in het bijzonder die het gezin of de familie betreffende, bleef niet achterwege. Instellingen van een meer republikeinsch karakter werden gedeeltelijk door monarchale vervangen, gedeeltelijk naar de minder

\footnotetext{
3 Zie: Wilken, Over de verwantschap en het huwelijks- en erfrecht bij de volken van het Maleische ras, blz. 10 vv. (Redactie).
} 
toegankelijke binnenlanden, tanah-talang, of naar het Westelijk deel van dit landschap verdrongen. Een dialect, dat sterke overeenkomst heeft met het Riouw-Linggasch Maleisch, de zoogenaamde Bahasa-Batinanam-soekoe, ontwikkelde zich aan de mondingen der Indragiri-rivier, een ander, de zoogenaamde Bahasa-Ringat, dat zich min of meer sterk naar het Riouw-Linggasch Maleisch heeft gewijzigd, breidde zich uit tot Batoe Sawal, terwijl de zoogenaamde Bahasa-Kwantan, stroomopwaarts van Batoe Sawal, en de Bahasa-Mamaq, in de binnenlanden, vooral tusschen de Simpang Kiri en de Tjenako, mindere afwijkingen van hunnen Menangkabauschen oorsprong vertoonen 4. Ook de inrichting van het gezin onderging langzamerhand wijzigingen. Waar de Djohorsche invloed zich het sterkst deed gelden, werd het matriarchale verwantschapsstelsel door het parentale vervangen, zonder dat evenwel alle sporen van de oorspronkelijke instelling verloren gingen, niettegenstaande de latere invoering van den Islâm, in het midden der 16e eeuw, ook hiertoe krachtig moet hebben bijgedragen. Hetgeen door Dr. Wilken in zijne "Verbreiding van het matriarchaat op Sumatra ", blz. 25, gezegd is omtrent het voorkomen van het matriarchat in min of meer zuiveren vorm in streken, waar het zoogenaamde Menangkabausch-Maleisch wordt gesproken, vindt dan ook hier volkomen bevestiging. Alleen moge de opmerking gelden, dat, waar moeielijk te overkomen natuurlijke grenzen ontbreken, deze vooral niet te scherp afgebakend mogen worden gedacht.

Met het bovenstaande voor oogen, zal het thans lichter vallen de verschillende vormen, waaronder het matriarchat hier voorkomt, nader te behandelen.

Het zuiverst vinden wij het matriarchale verwantschapsstelsel onder de zoogenaamde Orang-Mamaq, die aangetroffen worden in de TalangEko, de Talang-Djerindjing en de Talang-Kelajan, en langs den bovenloop der Tjenako en der Gangsal. Aan hun hoofd staat de To ${ }^{\varsigma}$

4 Uit deze mededeeling blijkt, dat op de, door de Heeren Holle en Brandes vervaardigde, taalkaart van Sumatra, voorkomende in het Koloniaal Verslag van 1887, de grens tusschen het Menangkabau- en het Riouw-Lingga-Maleisch, in het stroomgebied van de Indragiri, te veel Westelijk getrokken is. De lijn zou moeten gaan over het punt, waar de Eko zich rechts in de Indragiri ontlast, want hier ongeveer is Batoe Sawal gelegen. Zie: Wilken, De verbreiding van het matriarchat op Sumatra, blz. 25, noot 75, waar, ook ten aanzien van het stroomgebied van de Siak, het vermoeden wordt uitgesproken, dat de grenslijn tusschen de twee zooeven genoemde dialecten, het Riouw-Lingga- en het Menangkabau-Maleisch , Oostelijker moet loopen dan op de kaart van Holle-Brandes is aangegeven. (Redactie). 
Patih, die in de Talang-Kelajan woont. Zij volgen, zooals de Maleiers dit noemen, de langka-lama, en hebben grootendeels den Islâm nog niet aangenomen.

Het volk is verdeeld in soekoe's, waaronder hier verstaan worden alle afstammelingen uitslnitend in de vrouwelijke lijn van dezelfue stammoeder. De leden eener soekoe wonen bijna zonder nitzondering bij elkaar en zijn zeer nauw aan elkaar verbonden. De soekoe is verantwoordelijk voor de daden van elk harer leden, zooals blijken kan uit het gezegde: "mendapat sama belaba, kalilangan sama roegi, melompat sama patah, menjoesoep sama bongkokn.

Huwelijken in de soekoe zijn verboden. Het huwelijk, dat hier sěměndo genoemd wordt, heeft voor geen der partijen verandering van soekoe ten gevolge, want man en vrouw blijven ieder tot hume soekoe behooren. Slechts zelden heeft samenwoning plaats, waarbij dan de man bij de vrouw intrekt. Man en vrouw vormen geen gezin, want dit omvat hier alleen de vrouw met hare kinderen. Aan het hoofd van een dergelijk gezin, sěmandei, staat de oudste broeder der moeder, de mamaq, terwijl aan het hoofd der soekoe door de ooms van moederszijde een panghoeloe wordt gekozen, die door den vorst in zijne waardigheid bevestigd wordt. De natuurlijke vader heeft geene rechten op zijne kinderen; deze gaan geheel op in de soekoe der moeder, want ook de Orang-Mamaq zegt: "ajam djantan tidaq bertělor", dan wel: "ajam djantan tidaq membawa anaq".

Titels en waardigheden gaan nog uitsluitend in de vrouwelijke lijn over, terwijl wij ook in het erfrecht dezelfde beginselen toegepast vinden. De goederen, door den man vóór het huwelijk bezeten, de zoogenaamde hartă-pembawan, bestaande uit hetgeen hij door aanerving verkregen heeft, hartă-poesakă, en hetgeen hij door eigen arbeid heeft verworven, hartă-pentjarians, worden bij overlijden of scheiding het eigendom van zijne soekoe. De goederen, door, de vrouw vóór het huwelijk bezeten, de zoogenaamde hartă-dapatan, bestaande uit hare hartă-poesakă en hare hartă-pentjarian, blijven eveneens in hare soekoe. De goederen echter door beiden staande het huwelijk verworven, de zoogenaamde hartă-soearang, worden in twee deelen verdeeld: de eene helft vervalt aan de verwanten van den overledene, man of vrouw, de andere blijft het eigendom van den langstlevenden echtgenoot, weduwnaar of weduwe. Ook hier geldt dus de rechtsregel: "hartă-pembawan kombali, hartă-dapatan tinggal, hartă-soearang dibagi". Daar nu, volgens de opvatting der OrangMamaq, geen verwantschap bestaat tusschen den vader en zijne kin- 
deren, kunnen deze nooit bij diens overlijden van de hartă-soearang erven. Hij kan alleen, door schenking gedurende zijn leven, een deel hiervan in hun bezit stellen; doch nooit kan daarvoor de hartă-pembawan in aanmerking komen. Zoo worden ook de soekoegenooten van den man, bij diens overlijden, aansprakelijk gesteld voor zijne schulden, en kunnen de kinderen, uit zijn huwelijk voortgesproten, hiervoor niet in pandelingschap geraken; dit is wel het geval, zoodra de moeder met schulden sterft, daar deze meestal voor de helft door de kamanakan, voor de andere helft door hare eigen kinderen moeten worden voldaan $\mathbf{5}$.

Hebben over het algemeen de Orang-Mamaq slechts in geringe mate de Djohorsche en Mohammedaansche invloeden ondergaan, meer deden deze zich gelden bij de bevolking van de oevers der Indragiri-rivier of Batang Kwantan tusschen Tambangan en Batoe Sawal. Een gedeelte dezer streek, bevattende het gebied van Batoe Ridjal, Pranap en Pematang, staat bekend onder den naam van Tiga Loeroeng.

Ook hier treft men de verdeeling in soekoe's aan, aan wier hoofd een panghoeloe, gekozen door de mamaqs en bevestigd door den vorst, staat. Het begrip soekoe, zooals dit hierboven omschreven is, blijft hier onveranderd gelden, en het verbod, om in de soekoe huwelijken te sluiten, bestaat eveneens, ofschoon een zeer enkele uitzondering wel voorkomt.

Hoewel de echtgenooten ieder tot hun eigen soekoe blijven behooren, treft men hier bijna algemeen samenwoning van man en vrouw aan. De man trekt dan in het huis der vrouw, of bouwt een op zichzelf staande echtelijke woning op de plaats, waar de soekoe der vrouw gevestigd is. Dit laatste moet zeker ook er toe bijgedragen hebben, dat, naast de soekoe, het gezin, in dit geval bestaande uit de beide echtgenooten en hunne kinderen, zich begon te ontwikkelen. Toch blijft de vader weinig macht over zijne kinderen uitoefenen, daar deze tot de soekoe der moeder blijven behooren, en als zoodanig de oudste broeder van deze, de mamaq, het grootste gedeelte dier macht behoudt.

Op den regel, dat titels en waardigheden uitsluitend in de vrouwelijke lijn overgaan, komen hier meerdere uitzonderingen voor.

5 Dit is blijkbaar eene vergissing. Voor de schulden van de moeder kunnen alleen de eigen kinderen aansprakelijk zijn. Zie ook de mededeeling op de volgende bladzijde, regel 9 v. b. (Redactie). 
Wat het erfrecht evenwel betreft, zien wij hoe de hartă-pembawan en de hartă-dapatan het eigendom blijven van ieder der echtgenooten of van hunne soekoe en alleen de hartă-soearang voor verdeeling in aanmerking komen. Hierbij echter is het regel, dat eigen kinderen en zusterskinderen gelijke rechten op de nalatenschap hebben. Taat de man bij zijn overlijden schulden na, dan worden ook de kinderen voor de helft hiervan aangesproken, terwijl de andere helft door zijne soekoegenooten, in het bijzonder zijne kamanakans, moet worden voldaan. Laat de vrouw bij haar overlijden schulden na, dan zijn gewoonlijk de kinderen voor het geheele bedrag aansprakelijk, en kunnen zij dus hiervoor in pandelingschap geraken.

Bij echtscheiding wordt weder alleen de hartă-soearang in twee gelijke deelen tusschen de echtgenooten verdeeld; de kinderen kunnen geen aanspraak maken op een aandeel, doch volgen de moeder, zoodat zij, bij overlijden van hummen natuurlijken vader, ook niet van hem erven kunnen. Wanneer de vrouw hertrouwt, is haar aandeel in de hartä-soearang van het eerste huwelijk hartu-dapatan geworden, waarop haar tweede echtgenoot geene rechten kan doen gelden, evenmin als hare kinderen nit het eerste huwelijk een deel erlangen kunnen van de hartă-soearang van het tweede huwelijk, wanneer de tweede echtgenoot sterft. Komt echter de moeder te overljiden, dan hebben de kinderen nit het eerste huwelijk en die nit het tweede huwelijk evenveel rechten op haar aandeel in de harta-soearang.

Gaan wij nu over tot de beschouwing der bevolking stroomafwaarts van Batoe Sawal. Hier vinden wij nog sterkere overgangen tot het parentale verwantschapsstelsel. Wel is waar bestaat nog overal de soekoe, die een krachtigen band vormt onder hare leden, doch hare grenzen zijn minder scherp. Aan het hoofd van de soekoe stat de panghoeloe, gewoonlijk op dezelfde wijze gekozen, als hoven vermeld, en door den vorst bevestigd. Soms echter hebben, behalve de mamaqs, ook de weerbare mannen stem bij de keuze. Het gebeurt nu meermalen, dat hier leden eener soekoe zich, soms tijdelijk, afscheiden en elders zich neerzetten: zij blijven echter over het algemeen onder het toezicht van hunnen oorspronkelijken panghoeloe; slechts zelden wordt een afzonderlijke. panghoeloe aangesteld. Zoo is de bevolking stroomafwarts van Ringat, namelijk van 6 Pengalihan, Mompah,

- Voor de juiatheid van de spelling der volgende geographisehe namen kan niet geheel worden ingestaan, daar het handsohrift hier viet geer duidelijk is en atkortingen bevat. (Redactie). 
Pěkan Toewa, Kapal Petjah, S(oengei?) Bajas, S(oengei?) Bengkoewang, P(ěkan?) Djoemahat, P(ěkan?) Kemoedi, Pěkan Laïs, enz., voor zooverre deze niet bestaat uit anaq-radja's en hunne pandelingen, afkomstig van Kampong Bĕsar, K(ampong?) Poelau, Ringat, enz. Hieraan is het toe te schrijven, dat van Ringat tot $\mathrm{P}($ ěkan?) Pallas geen panghoeloe gevonden wordt, daar de panghoeloe niet wordt beschouwd als het hoofd eener streek, maar als hoofd eener soekoe. De hevolking stroomafwaarts van Ringat blijft dus onder het toezicht staan van hare panghoeloe's te Ringat, Kampong Běsar, enz.

Huwelijken in de soekoe komen veelvuldig voor, soms, in het bijzonder bij anaq-radja's, zelfs in graden van bloedverwantschap, die volgens den Islâm verboden zijn. Bij huwelijken tusschen twee personen van verschillende soekoe's is het zeldzaam, dat de echtgenooten ieder tot hun eigen soekoe blijven behooren. De man treedt in de soekee der vrouw of omgekeerd, hetgeen geheel afhankelijk is van de sterkte, de macht of het aanzien der soekoe. Wanneer dus de soekoe van den man krachtiger is, verlaat de vrouw hare kampong en wordt de echtelijke woning in de kampong der soekoe van den man gebouwd; de kinderen behooren dan tot die soekoe en heeft de mamaq over hen weinig of geen macht. Toch gebeurt het wel eens, dat bij echtscheiding, ook in het geval dat de soekoe van den man de sterkere is, de kinderen met de moeder naar hare soekoe terugkeeren. Alsdan geldt dus de regel: "ajam djantan tidaq membawa anaq", of zooals men ook hier zegt: "ajam berindoeq, serai beroempoen". Nog andere sporen van grootere macht in vroegere tijden treffen wij aan. Zoo heeft de soekoe der vrouw het recht, wanneer de man haar op reis wil meenemen, toe te zien, dat voor het noodige gezorgd is, zoodat zij geen gebrek zal lijden, terwijl het verlaten van het land voor Indragirische vrouwen, anders dan om de bedevaart te volbrengen, verboden is.

Ook in het erfrecht zien wij het parentale verwantschapsstelsel op den voorgrond treden. De regel dat de hartă-pembawan en de hartădapatan niet voor verdeeling in aammerking komen, wordt wel is waar nog gevolgd, doch daar na het huwelijk gemeenschap van goederen plaats vindt, is het onderscheid met de hartă-soearang allengs verloren gegaan, en komt het daarom meermalen voor, dat alles bij overlijden van een der echtgenooten onder den langstlevende en de kinderen verdeeld wordt. Zusterskinderen hebben geen aandeel in de nalatenschap, zoodra eigen kinderen aanwezig zijn. 
Bij echtscheiding ontvangen de kinderen geen aandeel in den boedel, daar deze tusschen de beide echtgenooten gelijkelijk wordt verdeeld, soms weder met inachtneming van den regel, dat de hartădapatan en de hartă-pembawan tot de oorspronkelijke eigenaars terugkeeren.

Schulden van een der beide echtgenooten of van beiden gaan bij overlijden op de kinderen over, die hiervoor in pandelingschap kunnen komen.

Overigens tracht men hier de verdeeling zooveel mogelijk naar de regelen van den Islâm te doen plaats vinden, hetgeen eehter meermalen te wenschen overlaat. Bij uitzondering komt taxatie naar de geldswaarde der nalatenschıp voor. Zoo wordt de echtelijke woning meestal aan de vrouw toegewezen, de sampan en tuinbouwgereedschappen aan den man. Sterft dus een der echtgenooten, dan komen de hem toe te wijzen goederen aan de kinderen, of, bij gebreke van kinderen, aan andere erfgenamen. Omtrent een groot gedeelte der nalatenschap geldt gewoonlijk de regel, dat, bij het landbouwend gedeelte der bevolking, de mannelijke en vrouwelijke erfgenamen gelijke aandeelen bekomen, terwijl bij de handelaars, meestal van vreemde af komst, de man het dubbele van het aandeel der vrouw erlangt.

Aan de mondingen der Indragiri-rivier komen nog de zoogenaamde Orang-Timor voor, die afkomstig zijn van eenige eilanden van den Lingga-archipel, in het bijzonder van Singkep, en van het landschap Reteh. Bij hen treft men het parentale verwantschapsstelsel aan, zooals dit voorkomt op de eilanden van den Riouw-Tingga archipel. 